\title{
Vídeo Terapia: La utilización de medios audiovisuales con fines terapéuticos
}

\author{
Adriana FARÍAS ${ }^{1}$ \\ adrianafarias50@gmail.com \\ Marcelo GonZÁLEZ MAGNASCO ${ }^{2}$ \\ foromercosur@gmail.com
}

Recibido: $16 / 06 / 14$

Aceptado: 02/11/14

\section{RESUMEN}

Este artículo aborda la experiencia del taller de Vídeo Terapia, que se realiza desde el año 2008 en el Servicio de Hospital de Día del Hospital Psicoasistencial Interdisciplinario José T. Borda, en la ciudad de Buenos Aires- Argentina. De esta manera, se busca plantear los principales aspectos teóricos que han servido de base para nuestro trabajo. Destacando las características específicas que hacen al contexto en que se desenvuelve el taller de Video Terapia, nuestras experiencias con los pacientes y la metodología de trabajo.

Palabras clave: vídeo terapia, dispositivo grupal, trabajo interdisciplinario, pacientes adultos con desórdenes mentales, transversalidad institucional

\section{Referencia normalizada}

FARÍAS A., GONZÁLEZ MAGNASCO M. (2014). "Vídeo Terapia: La utilización de medios audiovisuales con fines terapéuticos”. En Arteterapia: Papeles de arteterapia y educación artística para la inclusión social Vol.: 9. Páginas 273-288. Madrid.

\section{SUMARIO}

Introducción. Perfil de los pacientes. El vídeo como terapia. Dinámica del taller. Trabajo interdisciplinario y transversalidad institucional. Conclusiones. Agradecimientos.

\footnotetext{
${ }^{1}$ Psicopedagoga con formación en arte terapia. Es la cofundadora del Posgrado de Especialización en Arte Terapia del IUNA y actualmente su Directora. Investigadora universitaria categorizada. Dirección: Güemes 2952, Departamento de Audiovisuales del IUNA.

${ }^{2}$ Decano del Departamento de Artes Audiovisuales (IUNA) es psicólogo con formación en arte terapia. Fundador del Programa de Arte Terapia y cofundador del Posgrado de Especialización en Arte Terapia del IUNA. Investigador universitario categorizado. Dirección: Rocamora 4141, Departamento de Audiovisuales del Instituto Universitario Nacional del Arte.(IUNA).
} 


\title{
Video Theraphy: The use of audiovisual media for therapeutic purposes
}

\begin{abstract}
This article is about the experience of the workshop of Video therapy, which is carried out since 2008 in the Day Hospital Service at the Hospital Psicoasistencial interdisciplinary José T. Borda, in the city of Buenos Aires, Argentina. In it we consider the main theoretical aspects that have served as the basis for our work, the specific characteristics that make the context which it operates our workshop, our experiences with patients and work methodology.
\end{abstract}

Key words: video therapy, device group, interdisciplinary work, adults with mental dosorders, intitutional transversality.

\section{CONTENTS}

Introduction. Profile of patients. The video as therapy. Dynamic workshop. Interdisciplinary work and institutional transversality. Conclusions. Acknowledgements.

\section{Introducción}

El taller de Vídeo Terapia funciona en el Servicio de Hospital de Día del Hospital Psicoasistencial Interdisciplinario José T. Borda, hospital público y gratuito de la ciudad de Buenos Aires, Argentina desde el año 2008. El mismo, es un espacio de trabajo arte terapéutico con herramientas audiovisuales que se articula con el resto de actividades que ofrece el Hospital de Día, con el fin de promover y facilitar la recuperación de los pacientes que llegan a este Servicio. Además, es una instancia de articulación con la Universidad, pues sirve como espacio de práctica profesional para los estudiantes de licenciaturas del ámbito audiovisual del IUNA1 y para los estudiantes del Posgrado de Especialista en Arte Terapia que se imparte en la misma institución. ${ }^{3}$

La idea del taller de Vídeo Terapia nació en el año 2008 a raíz de una investigación-acción realizada entre el profesor Gabriel Perosino, docente de Iluminación y Cámara y el psicólogo con formación en Arte Terapia Marcelo González Magnasco. En aquella investigación se buscó observar los efectos terapéuticos que el uso del vídeo podía tener sobre un paciente afectado por esclerosis múltiple. El trabajo guió a esta persona en la realización de un filme, que él mismo escribió y que finalmente decidió actuar. La historia era en relación a su vida, ante el interrogante de cómo seguir viviendo con esta enfermedad. Tras el térmi-

\footnotetext{
${ }^{3}$ Comenzamos a trabajar en el año 1995 en el campo arteterapéutico dictando talleres e impartiendo seminarios, experiencia que cristalizó el año 2000en la creación del Posgrado de Especialista en Arte Terapia. Para más información ver Fundamentos en Arte Terapia, 2013, Buenos Aires, FEDUN
} 
no de esta experiencia y evaluando los buenos resultados obtenidos, nos planteamos la posibilidad de institucionalizar la experiencia y elaboramos una propuesta en conjunto con Adriana Farías. La misma fue presentada al Hospital Borda, donde desde el año 1997 venimos realizando -también con frecuencia semanal y en el Servicio de Hospital de Día- un taller de Arte Terapia.

Unos de los objetivo era aportar con una nueva instancia perteneciente al campo del Arte Terapia, y que como tal, comparte sus premisas, con la particularidad del uso de herramientas audiovisuales que para nosotros representaba variables distintivas y eficaces para nuestro contexto de trabajo. El Hospital de Día se caracteriza, entre otras cosas, por ser un dispositivo grupal en sentido doble: por un lado, atendemos a un grupo de pacientes ambulatorios que al hacer uso del Servicio se compromete a participar de todas las actividades de tratamiento, lo que implica asistir de lunes a viernes de 8:30 a 16:00 horas, el número de participantes generalmente es de quince a veinticinco pacientes; y por otro lado, la tarea que como profesionales desempeñamos en el Servicio es un trabajo grupal: en equipo e interdisciplinario, con objetivos compartidos. Es por ello, que la creación de un taller de Vídeo Terapia nos pareció no solamente necesario sino también pertinente. Teniendo en cuenta que la producción audiovisual por sus características refuerza el trabajo grupal, al ser necesario cubrir y articular una serie de roles tanto en lo que respecta a la producción en sí misma: guionistas, asistentes técnicos, director, actores, etc.

Otro objetivo general que distingue fuertemente a nuestro taller de Vídeo Terapia se encuentra estrechamente ligado a las múltiples posibilidades que abre en los distintos niveles implicados en la rehabilitación de los pacientes. El primero tiene que ver con la multiplicidad de transferencias que se generan en un taller de estas características, con muchos profesionales trabajando al mismo tiempo; el segundo con el desafío, en sentido positivo, que implica el aprendizaje de técnicas y herramientas nuevas que por sí mismas suelen generar un alto nivel de entusiasmo en los pacientes. Una tercer cuestión a destacar es el aspecto lúdico y creativo, en tanto el desarrollo del taller implica la producción de un cortometraje que se piensa y ejecuta en forma grupal. De esta manera se genera un espacio para la exploración, la distensión, la risa; y por último, aunque el taller no se enfoca en el aspecto dramático de la representación, el hecho de actuar, de ponerse en la piel de un personaje, y sobre todo el poder mirarse desde afuera en las distintas proyecciones que realizamos a lo largo del año, habilita tomas de conciencia que pueden ayudar de manera eficaz a los pacientes, situaciones que serán transmitidas en la Reunión de Equipo y serán tomadas por los terapeutas grupales en la terapia de grupo.

\section{Perfil de los pacientes}

Al taller de Vídeo Terapia asisten la totalidad de pacientes del Hospital de Día.

Los mismos poseen diferentes diagnósticos que van desde trastornos severos, cuadros depresivos graves; muchos de ellos presentan cuadros de diagnóstico 
duales y es frecuente que algunos de ellos, posean una larga historia de hospitalizaciones en distintos lugares.

La mayoría de los pacientes son de extracción social baja, con escasos recursos económicos y pocas conexiones o redes sociales de contención; usualmente, tampoco poseen ningún tipo de previsión ni obra social de respaldo. Asimismo concurren también un número menor de pacientes de extracción social media o alta debido a fracasos en tratamientos privados realizados con anterioridad.

Los pacientes son admitidos en el Servicio de Hospital de Día del Hospital Borda por diversas causas, entre ellas derivaciones internas de los otros servicios que funcionan en el hospital, así como por ingresos a través de consultorios externos; muchas veces son pacientes que han permanecido internados y se considera que pueden continuar el trabajo terapéutico en un espacio intermedio .

Por ende, el grupo que asiste al taller de Vídeo Terapia se caracteriza por su heterogeneidad. La presente situación hace necesario adecuar las consignas de trabajo y nuestra propia actitud como arteterapeutas en pos de atender las necesidades individuales de los miembros del grupo en relación con los objetivos terapéuticos que nos hemos planteado y las necesidades específicas de la producción audiovisual. En este sentido, decimos que nuestra propuesta es inacabada, pues se encuentra siempre en proceso y se adecua más a las particularidades del grupo y de la Institución que a una patología específica.

\section{Campo terapéutico de lo audiovisual}

Es determinante para la instalación del campo Arte Terapeútico la relación imaginaria que el arte mantiene con la sociedad, que le es o no permitido. Un acontecimiento fundamental ocurre en 1839 con la presentación del daguerrotipo3 que permitió el posterior desarrollo de la imagen fotográfica. El óptico Lerebours publica entre 1840 y 1844 lo que es considerado la primera colección de álbumes llamado, "Excursiones daguerriennes", La misma, estaba compuesta por daguerrotipos copiados en grabados, y realzados con personajes, barcos, carruajes y animales añadidos por el grabador; hechos todos ellos por fotógrafos de todo el mundo contratados por Lerebours. En 1842 el fotógrafo Carl F. Stelzner saca con daguerrotipo la que será la primera fotografía con cierto reconocimiento, un barrio de su ciudad, Hamburgo, desolado por un incendio. Esta nueva técnica fue ocupando el espacio de la reproducción de la realidad, desplazando a la clase artística. Diversas cuestiones llevaron al arte (y a sus diferentes lenguajes) a un proceso de introspección, un unevo discurso sobre sí mismo, al concepto de arte

\footnotetext{
${ }^{4}$ El daguerreotipo es reconocido como el primer procedimiento fotográfico. Presentado oficialmente en el año 1839. Fue desarrollado y perfeccionado por Louis Daguerre, a partir de las experiencias previas inéditas de Niépce (antes de1826), y dado a conocer en París, en la Academia de Ciencias de Francia
} 
por el arte, posiciones que legalizaron socialmente que el artista pudiera expresar su subjetividad en la obra.

La aparición de la reproducción mecánica de la realidad modificó la forma en que la sociedad se relaciona con el arte; se inauguró una nueva episteme (que decide que es y que no es arte) y abrió la posibilidad al surgimiento de nuevos y múltiples paradigmas. Podemos considerar que así como el imago mundis de la iglesia medieval ordenó la forma de producir, consumir y distribuir arte hasta mediados del siglo XIX, las tecnologías han tomado la posta, y es recién a partir del mediados del siglo XX con la aparición del chip y la popularización de las tecnologías, que hemos podido comenzar a pensar los efectos de estas en el mundo artístico y cultural.

Sin dudad la capacidad que tiene la humanidad de tener aparatos tecnológicos que reproducen mecánicamente lo real no solo permiten una nueva poética, sino que ha abierto impensables campos terapéuticos.

En la actualidad, desde niños hasta adultos mayores se mueven en el planeta con celulares capaces de sacar fotos y filmar. Muchos también tienen importantes dispositivos fotográficos o cámaras HD. Lo que crea una inmensa nube de fantasía de "todos podemos filmar, todos podemos hacer una película" similar al concepto "todos podemos dibujar". ¿Pero es tan así? ¿Es tan natural el lenguaje audiovisual? ¿Cómo producimos y mostramos, como filmamos y distribuimos?

En este marco, es un objetivo básico de la labor arte terapéutica construir un vínculo de confianza, como punto de partida, con los pacientes para que estos sean capaces de comunicar mediante imágenes, y en el caso del taller audiovisual, mediante imágenes en movimiento, sus angustias, sus ansiedades $u$ otros padecimientos, muchas veces silenciados por los límites verbales, que pudieran estar originados por la represión, inhibiciones o lo indecible de sus pensamientos, como así también aquello unido con el deseo ,el placer, los logros, los mundos imaginarios.

\section{Antecedentes}

Como hemos destacado anteriormente, si bien se encuentra situada dentro del campo arte terapéutico, los antecedentes más directos de la Vídeo Terapia lo podemos encontrar en lo que se ha denominado "Foto Terapia". Uno de los primeros trabajos relacionados pueden remontarse a $1856^{5}$, cuando Hugh W. Diamond, médico psiquiatra e investigador fotográfico británico, presentó ante la Royal Society una ponencia titulada "On the application of photography to the physiognomic and mental phenomena of insanity". Este psiquiatra británico se

\footnotetext{
${ }^{5}$ Diamond, Hugh W., "On the application of photography to the physiognomic and mental phenomena of insanity". Sander Gilman publica en el año 1976 The Face of Madness: Hugh W. Diamond and the origin of psychiatric photography, editado por Citadel Press in Secaucus, New Jersey.
} 
dedicó, entre otras cosas, a retratar pacientes más allá de la imagen como instrumento diagnóstico y con objetivos artísticos.

Ya en el siglo XX, la historia de la popularización de este campo puede comenzar a ser narrada cuando un pequeño anuncio apareció en la revista Psychology Today en 1977, solicitando entrar en contacto con profesionales que utilicen fotografía en su trabajo terapéutico; obteniéndose alrededor de doscientos respuestas que derivaron en la creación de "PhotoTherapy Quarterly Newsletter". La misma representa, la primera publicación específica sobre este tema. Posteriormente en el mes de mayo de 1979 se realizó en Illinois, (EE.UU.) el primer Simposio Internacional de Fototerapia. ${ }^{6}$

Rápidamente, esta agrupación de profesionales se transformó en la International PhotoTherapy Association, que modificó el newsletter por una publicación más académica denominada simplemente Photo Therapy, y que en su tapa y a manera de volanta se definía como una publicación multidisciplinaria internacional con el objetivo de expandir la utilización de la fotografía en espacios terapéuticos.

Ya en sus artículos puede verse una amplitud a nuevos espacios de trabajos y también aquellos relacionados a la imagen en movimiento, por ejemplo en el volumen 2, número 4 correspondiente a marzo de 1981 se incluye un artículo de Judith Rothschild llamado Photo therapy: Film animation as a therapeutic Tool.

Con mas de 3000 subscriptores dejó de publicarse la revista Photo therapy en el año 1987 y fue en Toronto, Canadá en 1984 que se realizó el último Congreso Internacional. Finalmente en 1988 dejó de funcionar la Asociación que los agrupaba. La foto terapeuta $\mathrm{J}$ Weiser considera que esto sucedió no por una falta de interés sobre este campo de trabajo sino, que al contrario, se debió al éxito alcanzado en los objetivos propuestos. En este sentido, es posible destacar que se comenzaron a publicar diferentes artículos sobre Foto terapia en revistas de asociaciones profesionales de psicólogos, psiquiatras, trabajadores sociales, etc.

Frank Gillette y Paul Ryan (quienes había colaborado en el área de investigación conducida por Marshall Mc Luham) crearon en 1969 el grupo Rain Dance en el cual realizaban trabajos de investigación con videos. En 1970 comienzan a editar la publicación Radical Software en la ciudad de Nueva York, donde se proclamaban como "El Movimiento Televisivo alternativo". Desde su óptica la TV era un vehículo altamente sofisticado y útil para el control social, capaz de manipular la opinión pública con facilidad. ${ }^{7}$ Por otro lado, autores como $\mathrm{McCu}-$ lloch y Wiener buscaron desarrollar la premisa de que si se comprende la forma en que nuestra cultura utiliza la información se puede estimar una serie de estrategias para descomponer el rígido mundo de la información. Dentro de esta táctica el video ocuparía un lugar privilegiado. Pensaban que revirtiendo el

\footnotetext{
${ }^{6}$ Historia y desarrollo de la Foto Terapia. Judy Weisser. www.phototherapy-centre.com

${ }^{7}$ Davidson Gigliotti. A Brief History of RainDance. ww.radicalsoftware.org/e/history.html
} 
proceso perverso de la televisión; abriendo al común de la gente (democratizando, popularizando) - mediante el uso de cámaras de video - el acceso a los medios de producción y distribución audiovisual. De esta manera, se les estaba otorgando mediante la toma del control de las propias imágenes, y por implicación, desde sus puntos de vista, el control de sus vidas, alejándolos del proceso de alienación que el sistema de producción capitalista arrastra consigo. La posibilidad de originar sus propias imágenes e información llevaría a los sujetos a un proceso de cambio (tanto personal como social y cultural). Otro de los principales conceptos que utilizaron para su desarrollado teórico fue el de Vídeoesfera de Gene Youngblood. $^{8}$

Los trabajos mencionados con anterioridad constituyen un primer acercamiento a un nuevo espacio de trabajo terapéutico, mostrándonos un esfuerzo para abrir puertas y expectativas tanto sociales como subjetivas. Estos primeros acercamientos tanto desde la fotografía como desde el vídeo se ubican temporalmente entre las décadas del 60 y del 70.

Dos variables podrían acercarnos a una explicación del desarrollo posterior, en relación con el Arte Terapia, que han tenido tanto la Foto Terapia como la Vídeo Terapia.

Por un lado, es necesario tener en cuenta la cuestión temporal. Las tecnologías de la fotografía y el vídeo son mucho más tardías o recientes en comparación con las artes visuales. La fotografía con daguerrotipos apareció en 1839 y en 1885 se hizo la primera presentación comercial de cine, por los hermanos Lumiére.

Por otro lado, y mucho más determinante, es el factor económico. Fue recién después de la segunda guerra mundial, con la aparición del transmisor y del chip, que se masificaron los mediosde producción audiovisual y fotográfica. Antes de este período los costos eran altísimos, recordemos que la fotografía no solo consistía en el aparato para capturar la imagen sino en el revelado, que insumía papel y otros artículos.

En relación a la imagen en movimiento, otro aspecto que pudo haber operado como obstáculo es la cantidad de personas que se necesita para poner en funcionamiento un filme y las características particulares que poseen los roles dentro del mismo.

En este sentido, la high tech ha permitido a la reproducción mecánica ocupar parte del lugar que la técnica manual imponía. Con la masificación de cámaras de fotos y filmadoras, su uso se ha democratizado.

En este sentido, una mayor cantidad de personas poseen la posibilidad de poner en marcha trabajos con medios audiovisuales, lo que deviene en una apertura

\footnotetext{
${ }^{8}$ Gene Youngblood's classic 1970 book on experimental film and video Expanded Cinema. Expanded Cinema. Gene Youngblood.Studio Vista, 1970. 460 pages.SBN: 0289701139
} 
de espacios para el trabajo clínico e investigativo dentro del cual se sitúa nuestro trabajo. Igual que en la larga historia del campo arte terapéutico la utilización de la producción audiovisual con objetivos terapéuticos fue introduciéndose de a poco. En principio usándose como complemento de alguna forma terapéutica, como el uso de webcam en terapias a distancia $u$ online, o aquel donde el rol del paciente es pasivo, en tanto se limita a observar ya sea la grabación de su sesión, una película o cualquier proyección cuyo fin sea ser utilizada como disparador para el trabajo posterior. Si bien hay aquí una relación con lo terapéutico, esta sería secundaria: el vídeo o lo audiovisual se utiliza como base u apoyo para la terapia.

Lo que hemos intentado introducir en los talleres de Video Terapia que hemos venido trabajando y presentamos en el presente artículo está relacionado a la perspectiva arte terapéutica del vídeo como terapia, donde el paciente ocupa un lugar activo como productor de sentido y de piezas audiovisuales, ya sea en la realización de producciones originales o en la selección y montaje de distintas piezas audiovisuales con un resultado original. Además, en el vídeo como terapia, lo terapéutico está estrictamente ligado con la realización en sí misma, en una relación de jerarquía sobre otros elementos presentes en cualquier taller audiovisual como el aprendizaje de técnicas y herramientas y el cuidado por lo estético.

En este punto es menester destacar que nos encontramos con un espacio de trabajo terapéutico nuevo pero que, al mismo tiempo, mantiene raíces con espacios que han tenido un desarrollo prolongado. Por un lado el campo de las llamadas terapias expresivas, en particular el Arte Terapia, entendida como la utilización de materiales y técnicas provenientes de las artes visuales. Y por otro lado, con lo que a partir de los años setenta se denominó como Foto Terapia o Terapia fotográfica, en EEUU o Europa. Al ser esta última el comienzo de la utilización de la reproducción mecánica de "lo real" con fines terapéuticos es que surgen los primeros trabajos con imágenes en movimiento y sonido con objetivos terapéuticos.

Por último, al igual que en Arte Terapia, en la Vídeo Terapia se espera que los pacientes puedan expresar a través de estas herramientas situaciones, malestares o sentimientos agradables o no, que se encuentran inhibidos y que todavía no encontraron su lugar en la palabra. Esto puede asumir distintas formas, como el caso de un paciente de 60 años que había trabajado toda su vida como obrero en una fábrica, con horarios apremiantes, había formado una familia, con una vida medianamente estable. Hasta que la pérdida de trabajo y una crisis en la familia producen un corte en su estructura psíquica, lo que determinó su internación. Luego de este período fue derivado al Hospital de Día. Estaba enojado y tenía algunas conductas persecutorias. En el taller de Vídeo empezó a sacar fotos, como primera experiencia en su vida, luego se animó a filmar y al final a actuar, cambió su estado de ánimo considerablemente y su recuperación fue muy bien evaluada dentro del Equipo Interdisciplinario.

Si bien todos las propuestas del Hospital de Día colaboraron en el mejoramiento de este paciente, creemos que el espacio del taller de Vídeo Terapia pudo 
habilitar paulatinamente capacidades que ni él mismo conocía, potenciales que la creación audiovisual en el contexto grupal permitieron que él paciente despliegue como producción subjetiva .

\section{La dinámica del taller}

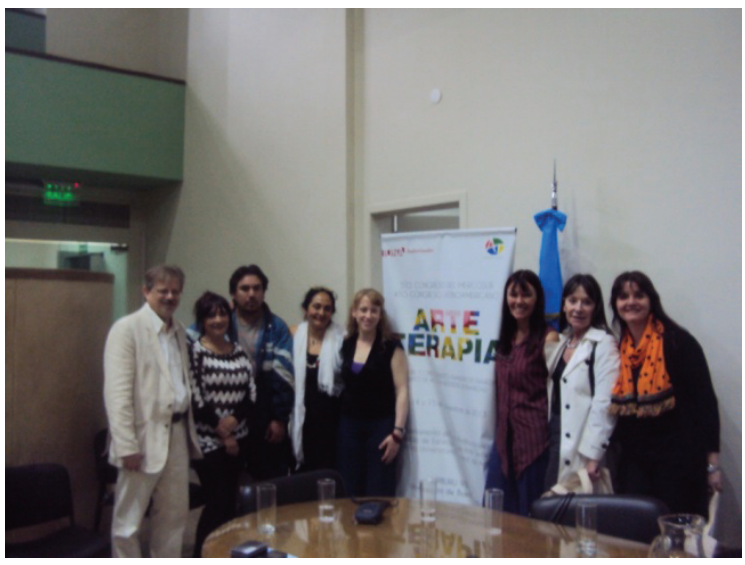

El taller en si mismo es un dispositivo grupal doble. En cuanto a los pacientes se desarrolla con el criterio de "grupo abierto", es decir, que el número de pacientes que compone el grupo tratado varía de acuerdo a ingresos que se producen de forma permanente y a altas terapéuticas o altas por abandono del tratamiento. Del lado del equipo profesional, trabajamos en el taller cinco profesionales ${ }^{9}$ de manera permanente más los pasantes que realizan su práctica especializada para el Posgrado de Especialista en Arte Terapia y Voluntarios de la carrera de Audiovisuales, ambos grupos pertenecen al Departamento de Audiovisuales del IUNA.

A nivel de la producción audiovisual desde el Taller se realiza todo el proceso de filmación de un cortometraje, lo que incluye las etapas previas al rodaje: la preproducción, la elaboración de una historia, el guion, la selección de locaciones, etcétera. Luego la producción del video en sí mismo y finalmente la etapa de la posproducción, que han sido resueltas de diferentes maneras, incluidos encuentros tipo asamblea de todos aquellos que han participado visualizando la producción y decidiendo qué tomas quedarán y cuáles serán excluidas durante el montaje. Con este objetivo en mente, realizamos un encuentro semanal donde jornada a jornada vamos desarrollando el proceso.

A nivel de objetivos terapéuticos nuestra propuesta se sitúa por un lado en el marco del Servicio de Hospital de Día, cuyos objetivos primordiales son la rehabilitación y la resocialización de los pacientes, y por otro lado, en los objetivos particulares que hemos definido en función del grupo específico con el que estemos trabajando. En general, buscamos fortalecer los vínculos interpersonales, desbloquear las posibles trabas que operen en el grupo, fortalecer la valoración

\footnotetext{
${ }^{9}$ El equipo está compuesto por Adriana Farías, Marcelo González Magnasco, Luis Corti, Graciela Berganza y Margarita Compañez Cutillo
} 
de sí mismos mediante la estimulación de sus posibilidades, y brindar un espacio de producción subjetiva a través de la creación y el ejercicio lúdico. Al igual que para nuestro taller de arte terapia, que se realiza en el mismo marco institucional, creemos que la expresión artística brinda la posibilidad de una zona intermedia. En palabras de Winnicott:

"La tarea de aceptación de la realidad nunca queda terminada, [...] ningún ser humano se encuentra libre de la tensión de vincular la realidad interna con el exterior, y [...] el alivio de esta tensión lo proporciona una zona intermedia de experiencia que no es objeto de ataques: las artes, la religión, etcétera. Dicha zona es una continuación directa de la zona de juego del niño pequeño que "se pierde" en sus juegos".

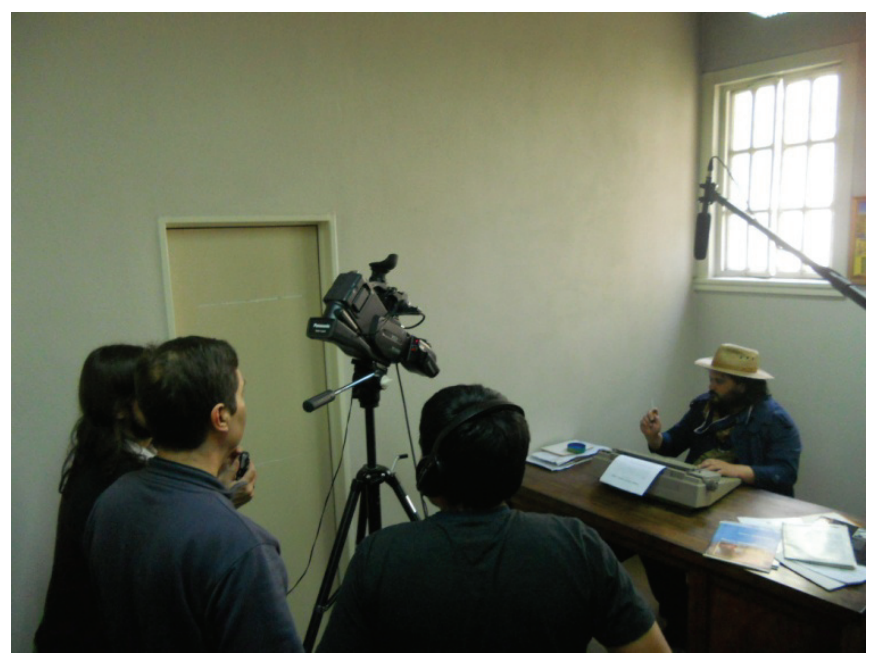

De esta manera, nuestros objetivos terapéuticos están ligados con favorecer, incentivar, proporcionar y propiciar dichos espacios de producción subjetiva dentro del taller.

La dinámica de cada encuentro se puede resumir en tres momentos que se ciñen a la fase del proceso de producción audiovisual en la cual nos encontremos:

-El primero es cuando planteamos la tarea a desarrollar en el día. Si hubo filmación en el encuentro anterior esta se revisa con el fin de evaluarla y corregirla

-El segundo es el desarrollo de la actividad en sí misma.

-El tercero es el cierre, donde se evalúa el resultado y la ejecución de la tarea, y se planifica para el siguiente encuentro.

La primera etapa del proceso en el taller de Vídeo Terapia consiste en encontrar una idea que pueda servir de base para la historia y el guion del cortometraje. Esto suele ocurrir de manera espontánea: un paciente o varios traen una idea y lo que se hace es consensuar entre todos esas propuestas. 
En este sentido debemos recordar que nuestros pacientes asisten también a otros talleres dentro del Servicio de Hospital de Día cuyas experiencias les pueden servir como disparadores. Tal es el caso del taller de arte terapia, músicoterapia o terapia ocupacional, sin contar con la asistencia a sesiones de terapia grupal.

Sin embargo, hay ocasiones en las cuales resulta complejo que los pacientes encuentren una historia; en estos casos recurrimos a una serie de estrategias de resignificación del trabajo creativo de terceros que pueden funcionar como disparadores de ideas.

Una de ellas es el visionado, que consiste en la proyección de cortometrajes, escenas de películas o publicidades que se proyectan en el espacio del taller de acuerdo a los intereses del grupo y a los objetivos terapéuticos establecidos para él. Otra estrategia que hemos utilizado es la música: mediante la escucha activa de canciones o melodías intentamos extraer de ellas emociones o historias. Una tercera estrategia consiste en mirar libros de arte o leer cuentos y poesías.

En cierta ocasión estábamos tratando de encontrar una historia. Un miembro del equipo profesional trajo para el siguiente encuentro un libro con la vida y obra del artista austríaco Friedensreich Hundertwasser ${ }^{10}$. Este libro y sus imágenes y el artista mismo, llamó inmediatamente la atención de uno de nuestros pacientes, que pidió llevárselo para poder leerlo con más calma. Al siguiente encuentro el paciente venía con una idea para convertir en historia: él sería Hundertwasser y se encontraría de paso por Buenos Aires presentando una muestra en el Museo de Bellas Artes. Al resto del grupo le gustó la idea y se comenzó a trabajar entonces en la creación de la historia. Hay que tener en cuenta que como mínimo los grupos se componen de quince pacientes, por ende las ideas deben trabajarse mucho y modificarse con el fin de poder involucrar a todo el grupo.

La idea inicial de esta historia, se transformó entonces en un guion donde había un set televisivo en el que funcionaba un noticiero. Desde el estudio El artista era entrevistado y evaluado por los periodistas y por críticos de arte que se encontraban en el estudio y el conductor del noticiero se comunicaba con un móvil ubicado en el Museo de Bellas Artes donde se encontraba la muestra de Hundertwasser y el público espectador. Luego, en un momento dado, se interrumpía la transmisión para dar paso a una noticia de último minuto que daba cuenta de la pelea entre los jugadores de un equipo de fútbol que se disponían a empezar un partido. Hundertwasser se ofendía por la interrupción para mostrar ese tipo de noticias vanas...y continúa.

\footnotetext{
${ }^{10}$ Artista nacido el 15 de diciembre de 1928 en Viena y fallecido el19 de febrero de 2000. Austriaco multifacético, que se desempeñó en diversas áreas de conocimiento como la pintura y la escultura haciendo diseños de edificios originales
} 


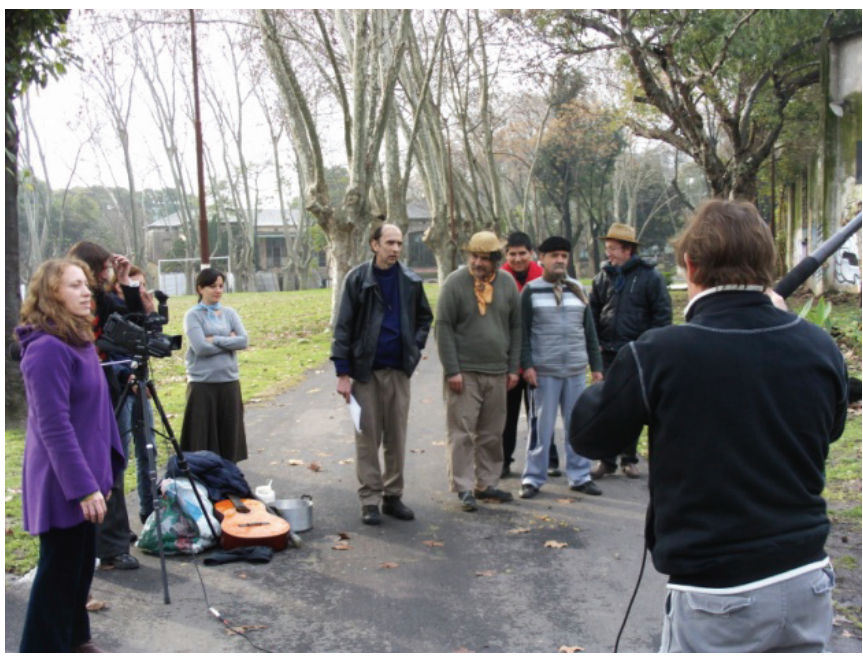

Esta historia refleja la manera de trabajar, una vez que se tiene la historia, se realiza la escritura generalmente en forma grupal. A veces sucede que hay un paciente con mucha motivación por la creación y escritura de historias, así que si sus compañeros están de acuerdo se delega en él la elaboración total.

Aunque de la misma manera que sucede con las ideas, el guion solo sirve como pauta general, ya que suele modificarse sobre la marcha atendiendo a las distintas situaciones que puedan surgir durante el rodaje.

Los siguientes pasos son los comunes a cualquier trabajo audiovisual: el armado del storyboard y la escritura del guion, que se realizan también en forma grupal y asistidos por nuestro equipo.

Luego se distribuyen los roles que cada uno de los pacientes ejercerá: dirección, cámara, sonido y asistente de dirección, asistente de cámara, asistente de sonido y actores. Esta distribución atiende a los deseos de los pacientes. Por último se seleccionan las locaciones, siempre dentro del Hospital, se escoge el vestuario y se arman las escenografías si es necesario.

El proceso se cierra con la fase de posproducción y proyección del cortometraje realizado. Una vez que el cortometraje está listo se estrena en el espacio de nuestro taller en primer lugar para nuestros pacientes y el equipo del taller. Esta es quizás una de las instancias más felices, los pacientes ven el resultado del trabajo sostenido durante todo un semestre. En una segunda instancia convocamos a las familias de los pacientes e invitamos al resto de profesionales que conforman el equipo del Hospital de Día.

Además de planear y ejecutar todos los pasos de la realización de un cortometraje, el taller de Vídeo Terapia incorpora otras actividades relacionadas a la producción audiovisual y que sirven de apoyo para la realización. Nos referimos 
a capacitaciones de maquillaje y efectos especiales y a la confección de collages a partir de imágenes sacadas de revistas e historias creadas en base a fotomontaje. Estas últimas con el objetivo de introducir en los pacientes nociones básicas de la estructura del relato audiovisual y la importancia del montaje en la construcción de su sentido.

Además de filmar las escenas del cortometraje filmamos gran parte del proceso de rodaje en un registro del backstage. Uno de nuestras convicciones con respecto al uso de herramientas audiovisuales para fines terapéuticos, tiene que ver con la toma de conciencia que posibilitan al permitirle a nuestros pacientes verse, literalmente, desde afuera. El registro del backstage es la manera en cómo nosotros reforzamos esta posibilidad, mediante la proyección que encuentro a encuentro vamos realizando de las tomas que se hicieron el encuentro anterior, donde incluimos las tomas del cortometraje propiamente tal y las tomas del backstage. Si bien el objetivo Explícito es que podamos hacer evaluaciones técnicas de las escenas para corregir las tomas siguientes, es igualmente un objetivo que los pacientes se vean en la pantalla trabajando, actuando e interactuando con sus compañeros y con nosotros.

Este proceso, el teórico y vídeo-artista, Paul Ryan, lo denominó self cybernation $^{11} \mathrm{y}$ consiste en el impacto psicológico que tiene para las personas el verse y escucharse en una pantalla. Aunque esta experiencia sea común el día de hoy, donde la tecnología es mucho más accesible, nuestros pacientes generalmente no han tenido siquiera la oportunidad de manipular cámaras fotográficas y mucho menos han sido grabados y proyectados en pantallas grandes.

Para Ryan el hecho de verse y de haber participado en la grabación de ese registro audiovisual supone una ruptura epistemológica, que si bien la pensaba en relación con el rol que en los años setenta se imaginaba para el vídeo y la televisión como motores del cambio social, nosotros la tomamos como parte de los efectos terapéuticos a nivel subjetivo que brinda el taller. Tiene que ver con la posibilidad que se le brinda a pacientes, generalmente de escasos recursos, de manipular herramientas sofisticadas, de desafiarlos a aprender y realizar un proceso de alta complejidad como lo es la filmación de un cortometraje, cuestiones que sin duda repercuten en la valoración de sí mismos y habilitan, junto con el visionado del backstage, tomas de conciencia importantes para su proceso de recuperación.

\footnotetext{
${ }^{11}$ Ryan, Paul, Birth and Death and Cybernation: Cibernetics of the Sacred, Nueva York: Gordon \& Breach

Publishing Group, 1973
} 


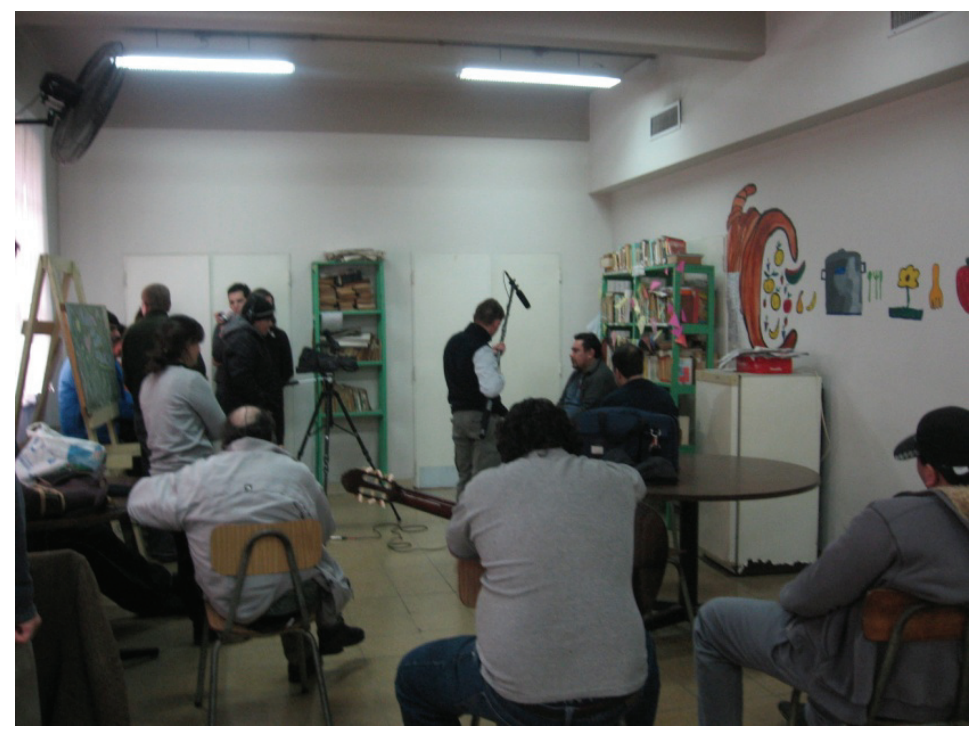

\section{Trabajo interdisciplinario y transversalidad institucional}

La evaluación y las intervenciones que como profesionales realizamos en el espacio de Vídeo Terapia, están estrechamente ligadas al modo de trabajo que opera en el Servicio de Hospital de Día.

Las intervenciones que hacemos en el taller se atienen al mismo modus operandi del taller de Arte Terapia que realizamos en el Hospital: intervenciones de tipo pedagógico, terapéutico y estético. Pero estas intervenciones como también las evaluaciones están siempre mediadas y sujetas por el trabajo interdisciplinario que realizamos en el Servicio, y que se hace visible en las reuniones generales que de modo semanal realizamos entre todos los miembros del equipo. En ellas cada uno expone las experiencias de los talleres, de las sesiones psicoterapéuticas grupales,

y también el equipo de enfermería cuenta su experiencia. El objetivo es hacer circular la información con el fin de delinear estrategias en común, también ayuda a que los profesionales podamos tener una visión más compleja de nuestros pacientes puesto que ellos suelen hacer distintos tipos de despliegues en cada espacio. La reunión de equipo es obligatoria y permite el movimiento interdisciplinario necesario para evitar conductas iatrogénicas.

En este punto nos acercamos al concepto de "transversalidad institucional", imaginado a principios de los 60' por Félix Guattari. En su libro Psicoanálisis y transversalidad Guattari propone que cualquier acontecimiento ocurrido en una de las partes del dispositivo institucional repercute en el dispositivo en su totalidad. De la misma manera, creemos que en nuestro trabajo interdisciplinario, 
todos los trabajos y actividades propuestos a los pacientes en el marco del Hospital de Día repercuten de una manera u otra en su tratamiento global.

Es el caso de uno de nuestros pacientes que en un cortometraje representaba a un sujeto que acudía a la consulta de su psicólogo para hablar con él de sus problemas conyugales. En la vida real este paciente presentaba una actitud de indiferencia en las sesiones de terapia grupal a la que diariamente asisten los pacientes del Hospital de Día. Esta resistencia se manifestó en la actuación de la escena donde su personaje debía escuchar a su psicólogo y fue necesario rodar las escena varias veces antes de que él pudiera permanecer sentado, mirar y escuchar lo que el psicólogo ficticio tenía para decirle. A partir de este espacio que fue muy lúdico, donde nos reímos, tuvimos que grabarlo varias veces, él pudo traspasar este cambio que operó en la representación al espacio de la terapia grupal y cambiar su actitud de indiferencia por una de escucha activa tanto hacia su psicólogo como a sus compañeros. Además siendo una persona con muy pocas posibilidades de hablar, muy tímida, en el taller ocupó un lugar central por lo menos de cuatro cortos, el espacio le sirvió para circular de otra manera con sus compañeros y en general.

El tema de la transversalidad está ligado con lo que se llama multitransferencia, es decir, la persona tratada en un dispositivo donde hay un equipo de personas va a ir generando transferencia con los diferentes profesionales. Esa multiplicidad de transferencias permite que este sujeto tenga la posibilidad de hacer despliegues afectivos diferentes. Desde ya existen situaciones que pueden emerger en el taller, pero que luego son elaborados en el espacio de la psicoterapia. Esto puede llevarse adelante por el intercambio entre los profesionales en las reuniones de equipo que se realizan semanalmente. Básicamente lo que se hace es el pasaje de información de la situación, de qué es lo que pasó, cómo se eligieron determinadas temáticas, esto permite que se evalúe en forma contextualizada e interdisciplinaria. Y el segundo modo es la información que los mismos pacientes llevan como temática a su terapia, o sea que de un lugar o de otro lo que haya acontecido en el espacio de audiovisuales va a ser un posible tema de elaboración.

\section{Conclusión}

Podemos decir que este espacio ha sido una construcción dentro del Hospital de Día, significativamente valiosa. Un espacio posible ligado a las oportunidades que brindan las mismas herramientas técnicas con las que se trabaja. Muchos pacientes nunca han trabajado con equipos audiovisuales y el acceso a estos, hace que puedan manifestar expectativas que quizás en otros lugares no despliegan y genera un entusiasmo que creemos es fundamental para el cumplimiento de los objetivos generales. Un espacio lúdico que permite un acercamiento vincular entre todos los participantes. Podemos decir una transformación desde lo creativo y desde los aspectos sanos de sus participantes.

Hasta el momento se han filmado y 15 cortos. El último fue estrenado y presentado por uno de los participantes en el 5to. Congreso del Mercosur y 4to. Latinoamericano, realizado el 13, 14 y 15 de noviembre 2013 en Buenos Aires. 
También se han hecho otras presentaciones, siempre en contexto académico o profesional y con la autorización de nuestros pacientes (Ver Anexo)

\section{Agradecimientos}

Por último, los autores quisiéramos agradecer al Dr. Lucio Mastrandrea, al Dr. Javier Cabello; a la Lic. Marcela Rigone de Montes; a las Arte-Terapeutas: Graciela Berganza y Margarita Compañez Cutillo a Luis" Lucho" Corti especialista en audiovisuales, a Virginia Vallés que tan bien comprende cuando llega el momento de editar. A Malena González Magnasco.

Todo esto habría sido imposible sin la colaboración de los docentes, no docentes y todos los voluntarios y pasantes del IUNA junto con el equipo profesional del Servicio del Hospital de Día del Borda.

\section{Referencias bibliográficas}

FARIAS, A, GONZALEZ MAGNASCO, M (2013) Fundamento en Arte Terapia. Ed.FEDUN

GILMAN, S (1976) Face of madness: Hugh W. Diamond and the Origin of Psychiatric Photography. Nueva Jersey, Brunner Routledge.

GIGLIOTTI, D (2003) “A Brief History of RainDance". En www.radicalsoftware.org/e/history.html

GUATTARI, F (1976) Psicoanálisis y transversalidad. Buenos Aires, Siglo XXI.

RUBIN, J (1982) "Art Therapy. What it is and what it is not". En American Journal of Art Therapy, vol. 21.

RYAN, P (1973) Birth and Death and Cybernation: Cibernetics of the Sacred. Nueva York, Gordon \& Breach Publishing Group.

WEISER, J (2001-2014) "History and Development" y "Compared with Other Fields".

En www.phototherapy-centre.com/home.htm.

YOUNGBLOOD, G (1970) Expanded Cinema. Nueva York, P. Dutton \& Co.

WINNICOTT, D (1980) Realidad y juego. Buenos Aires, Gedisa. 